\title{
Research@ZaB: FDS Features for Pressure Loading Assessment Within the Context of the Train-Tunnel Model Development
}

\author{
Aliaksei Patsekha and Robert Galler \\ Chair of Subsurface Engineering, Montanuniversität Leoben, Leoben, Austria
}

Received October 16, 2021; accepted October 29, 2021; published online November 29, 2021

\begin{abstract}
The CFD model of the train-tunnel system, previously developed on proven analytical dependencies, is improved by the introduction of a tunnel cross-passage and the consideration of surface roughness. These additions bring the simulation setup closer to real conditions allowing to explore the FDS features in the evaluation of the aerodynamic effects occurring in a tunnel. Pressure and velocity patterns are obtained for the resulting model of a high-speed train in a tunnel with a cross-passage. The maximal and minimal pressure levels for the tunnel and the cross-passage spans are calculated to provide the data for the design phase and safety assessment. The approach to determine the most loaded surfaces of the tunnel and its inner structures, e.g. escape doors, for an estimation of their operational reliability is discussed. The study shows that the FDS software can be a helpful tool in assessing scenarios where the train-tunnel interaction is reviewed, though its applicable capabilities and set of features are largely dependent on the tasks to solve and need to be accurately adjusted.
\end{abstract}

Keywords: Aerodynamic loading, Pressure, Rail tunnel, High-speed train, Simulation, Fire Dynamics Simulator

\begin{abstract}
Research@ZaB: FDS-Eigenschaften zur Bewertung der Druckbelastung im Rahmen einer Zug-TunnelModellentwicklung
\end{abstract}

Zusammenfassung: Das bisher auf bewährten analytischen Abhängigkeiten entwickelte CFD-Modell des Zug-TunnelSystems wird durch die Einführung einer Tunnelquerung und die Berücksichtigung der Oberflächenrauheit verbes-

\footnotetext{
A. Patsekha $(\bowtie)$

Chair of Subsurface Engineering,

Montanuniversität Leoben,

Erzherzog Johann Straße 3,

8700 Leoben, Austria

aliaksei.patsekha@unileoben.ac.at
}

sert. Durch diese Ergänzungen wird der Simulationsaufbau näher an die realen Bedingungen herangeführt und ermöglicht es, die FDS-Eigenschaften bei der Bewertung der in einem Tunnel auftretenden aerodynamischen Effekte zu untersuchen. Im resultierenden Modell werden Druckund Geschwindigkeitsprofile eines Hochgeschwindigkeitszuges in einem Tunnel mit Querschlag ausgegeben. Dabei werden die maximalen und minimalen Druckniveaus für den Tunnel und die Querschläge berechnet, um die Daten für die Planungsphase und die Sicherheitsbewertung bereitzustellen. Der Ansatz zur Ermittlung der am stärksten belasteten Oberflächen des Tunnels und seiner inneren Strukturen, z. B. Fluchttüren, zur Einschätzung ihrer Betriebssicherheit, wird diskutiert. Die Studie zeigt, dass die FDS-Software ein hilfreiches Werkzeug bei der Bewertung von Szenarien zur Überprüfung von Zug-Tunnel-Interaktion sein kann. Obwohl ihre anwendbaren Fähigkeiten und Funktionen weitgehend von den zu lösenden Aufgaben abhängen und genau angepasst werden müssen.

Schlüsselwörter: Aerodynamische Belastung, Druck, Eisenbahntunnel, Hochgeschwindigkeitszug, Simulation, Fire Dynamics Simulator

\section{Introduction}

Train aerodynamics presents significant challenges to highspeed operation not only in the open air but also and especially in tunnels. Aerodynamic drag, slipstream, piston effect, pressure, and micro-pressure waves are among the problems caused by a railway train passing at high speed through a tunnel [1,2].

Railway tunnel construction is a kind of sophisticated and systematic engineering, where the phenomenon of overpressures represents one of the most challenging aspects to consider in the design phase. One of the questions from the specified area concerns a decision on the fire-protection doors of cross-passages. Operational re- 
liability and durability of these doors, decided in particular by their resistance against pressure variations, provide an escape path into a safe area during an incident and guarantee the protection of the cross-passage components [3]. Depending on the tunnel dimensions and the frontal area of the train, alternating loads of over $\pm 10 \mathrm{kPa}$ can arise [4]. However, there are no precise technical regulations which define uniform requirements of doors in tunnels [5]. Though some of the standards cover aerodynamic load-related questions, e.g. a general introduction to high-speed rail aerodynamic phenomena for the tunnel environment is given in [6], methodologies for quantifying the pressure changes, train-tunnel pressure signature, and pressure loading on trains in tunnels are discussed in [7] and maximum pressure variations in tunnels are considered in [8].

Hence the technical conclusions made in the design phase are based on project-related individual solutions. For example, the cross-passage doors were specifically designed for the Gotthard base tunnel considering the dynamic differential pressure of $\pm 20 \mathrm{kPa}$ for more than one million load cycles [9].

Thus, the assessment of pressure loading caused by trains meeting or passing in tunnels is of great research interest because the analytical approach to solve the abovelisted tasks is not fully developed at the moment. For example, no formulae are available for the case of trains meeting in tunnels. In current conditions, computational fluid dynamics (CFD) could be the only predictive tool capable of coping with all the aspects of this problem [10].

Recent studies prove the usefulness and reliability of CFD techniques to investigate the aerodynamic phenomenon related to train-tunnel systems [11-14]. The current research is devoted to further assessment of Fire Dynamics Simulator (FDS) in the capacity of modelling software to predict the aerodynamic pattern of the traintunnel interaction. It is worth noting that FDS is not among the most popular simulation packages to solve the abovementioned tasks for the following reasons: the geometry is based on a rectilinear mesh; only static solid objects are available for calculations; the program code is not totally adjusted for high-speed flow analysis. Nevertheless, FDS is a proven simulation tool confirmed by multiple verification and validation cases to study aerodynamics $[15,16]$.

\section{Research Approach and Methodology}

FDS (version 6.7.5) is used to assess the aerodynamic performance of a high-speed train passing through a tunnel. The simulation setup was compiled involving the proven analytical dependencies for the airflow characteristics in the previous research phase [17]. The FDS model and parameters were adjusted according to the study purpose - to investigate the aerodynamics of the train-tunnel system.

The FDS capabilities to assess the high-speed train impact on pressure pattern inside a railway tunnel were explored in two scenarios in which a tunnel without and with a train inside was considered. Additional steps to bring the model setup closer to reality include the introduction of the auxiliary or technological structures and the surface roughness consideration.

Thus, a cross-passage ( $4.8 \mathrm{~m}$ in width) to investigate the influence of a possible structural change in the tunnel on the aerodynamics profile is introduced. Within the study, it allows defining a pressure impact to constructional elements of the tunnel, like doors of a cross-passage. The impact assessment of the roughness for the tunnel and train surfaces completes the survey.

This task definition sets the following scenarios:

- Empty tunnel with a cross-passage;

- Train in the tunnel with a cross-passage;

- The case where roughness is considered for the tunnel and the train surfaces.

The train model with a length of $80.6 \mathrm{~m}$ in the $300 \mathrm{~m}$ tunnel with a cross-passage is given in Fig. 1.

The FDS output devices to record pressure, velocity, and volume flow quantities are included in the model. The terms "centerline" and "side" characterize a linear positioning of measuring points: the central axis of the tunnel (coordinates $Y=0, Z=3.4 \mathrm{~m}$ ) and the lengthwise axis at the left tunnel side where a cross-passage is situated (coordinates $Y=2.6 \mathrm{~m}, Z=1.6 \mathrm{~m}$ ), respectively.
Fig. 1: The FDS train model in the tunnel with a cross-passage

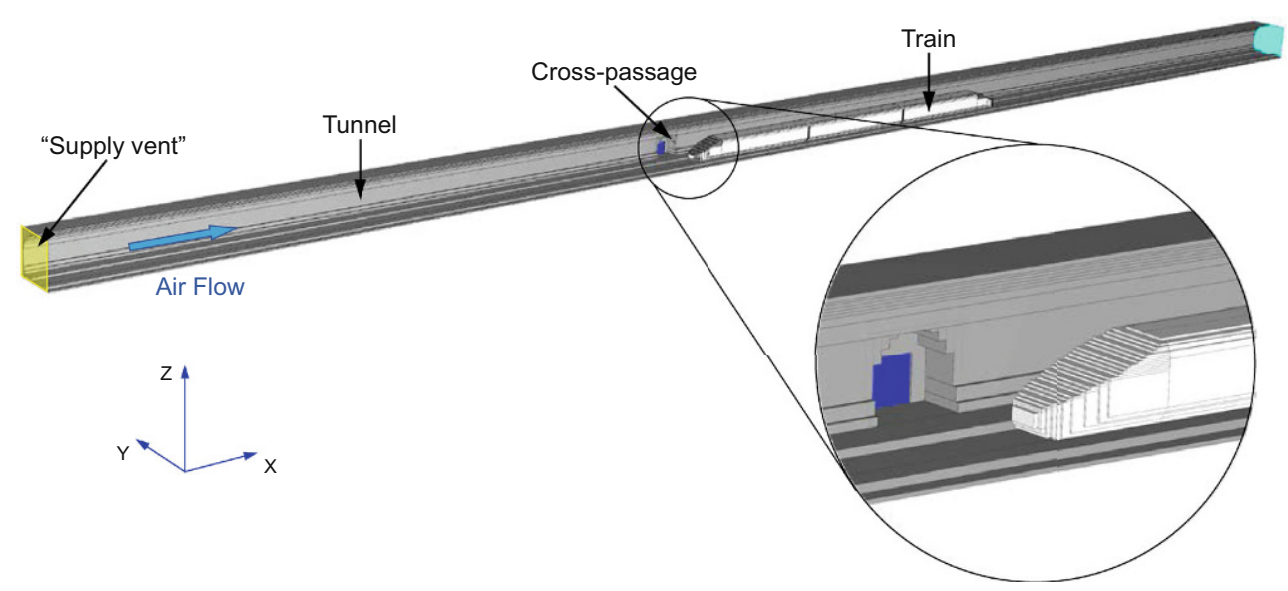




\section{Results and Discussion}

The train-tunnel model development leads to the detailed study of the following cases.

\subsection{Prediction of Aerodynamic Parameters for the "Tunnel with a Cross-passage" Case}

Three different cross-passage locations at a distance of 70 , 158 , and $250 \mathrm{~m}$ from the supply vent that affect aerodynamics inside the tunnel are considered. The averaged parameter values for a period of steady conditions, from 15 to $20 \mathrm{~s}$ of the simulation, are used for the analysis.

Every cross-passage location provokes side pressure fluctuations within its boundaries (Fig. 2). Mean pressure losses demonstrate similar behaviour but with a lesser magnitude. Meanwhile, pressure values measured at the tunnel centerline have no explicit dependency on the presence of a cross-passage in the area.

A cross-passage itself as well as its proximity to the tunnel entrance (position of the air supply vent in the model) increases the pressure losses for a certain scale as there are very close pressure levels for cross-passages at a distance of 158 and $250 \mathrm{~m}$.

Horizontal pressure profiles through the tunnel longitudinal cross-section with shown pressure distribution inside the cross-passage area are given in Fig. 3.

The analysis of the obtained velocity profiles and corresponding cross-passage locations shows a temporary drop of an equal magnitude for every case in side velocity values appearing just after each cross-passage as well as no considerable changes in the centerline velocities.

\subsection{Prediction of Aerodynamic Parameters for the "Train in the Tunnel with a Cross- passage" Case}

In this section, the aerodynamic parameters for the model of a tunnel with a cross-passage and a train inside are discussed. The distance between the supply vent and the train is set at $120 \mathrm{~m}$. Seven locations of a cross-passage (70, 115.2, 120, 158, 195.2, 200, and $250 \mathrm{~m}$ from the tunnel entrance and the supply vent) are analysed to determine caused changes in pressure and velocity levels.

Fig. 2: Impact of the cross-passage location on side pressure values
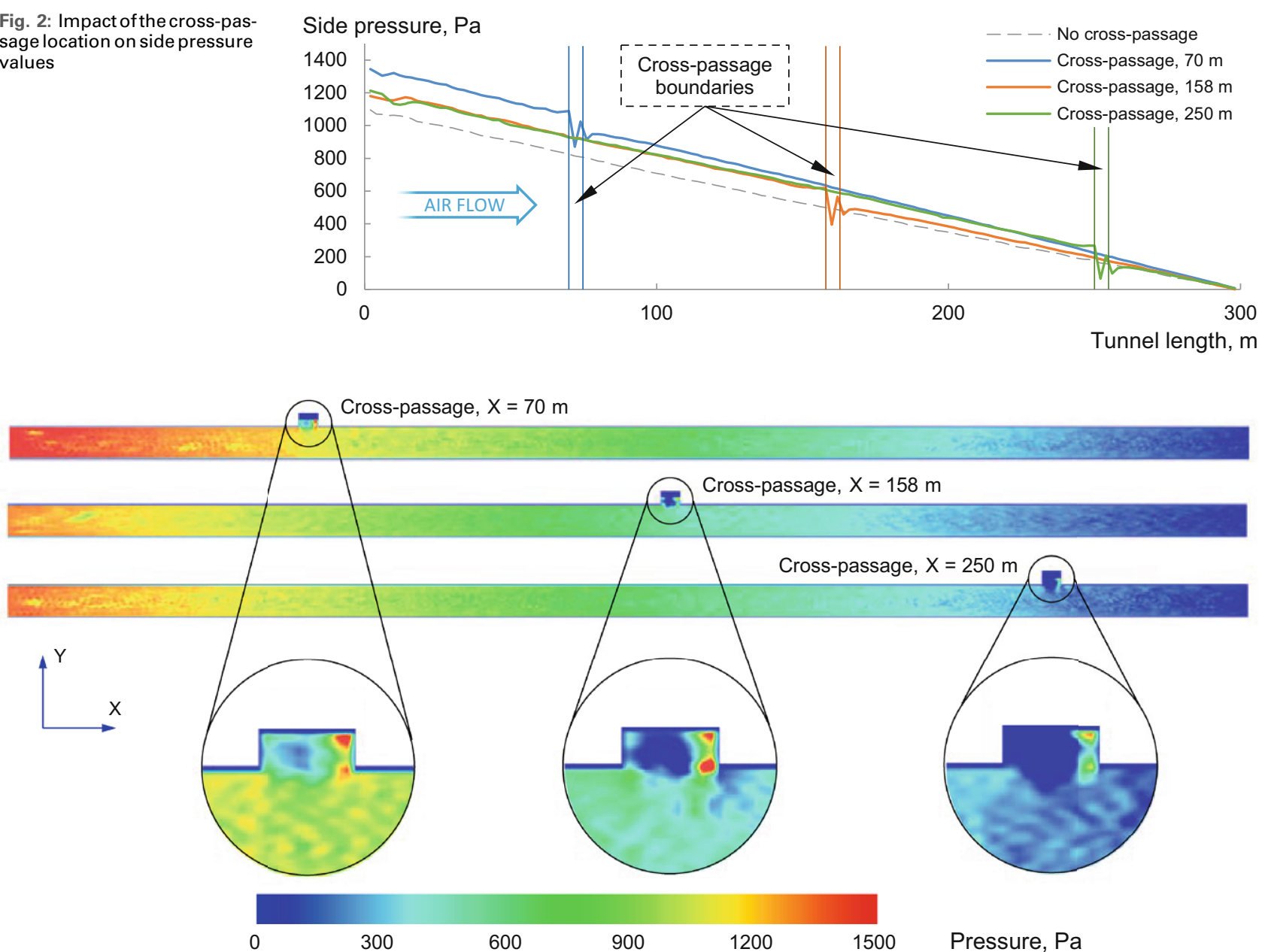

Fig. 3: Pressure profiles of the tunnel longitudinal cross-section (plane $Z=1.6 \mathrm{~m}$ ) with cross-passage locations at 70,158, or $250 \mathrm{~m}$ from the supply vent (at $18 \mathrm{~s}$ of the simulation) 
Fig. 4: Impact of the cross-passage position on the side pressure values through the tunnel length
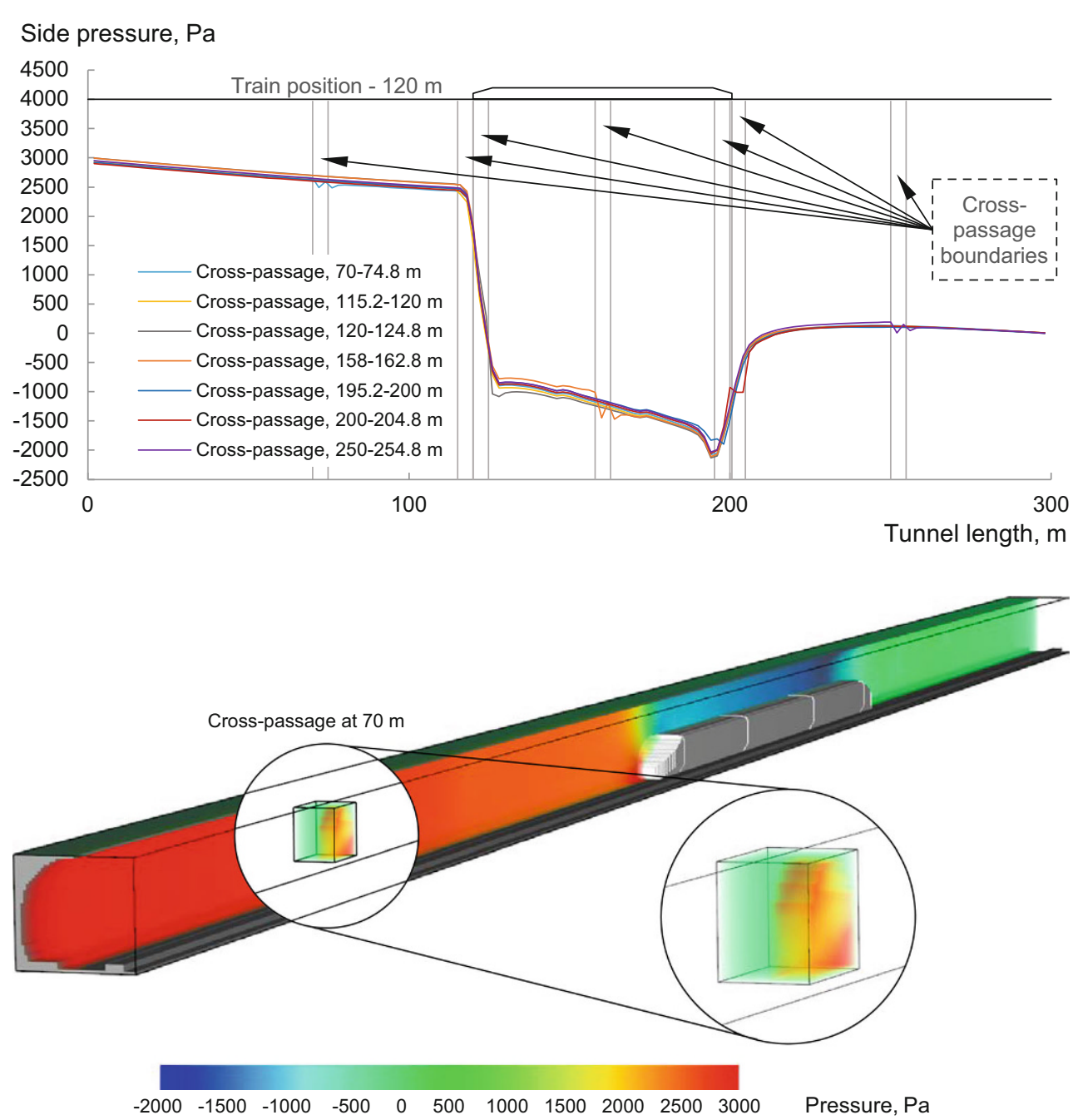

Pressure, $\mathrm{Pa}$

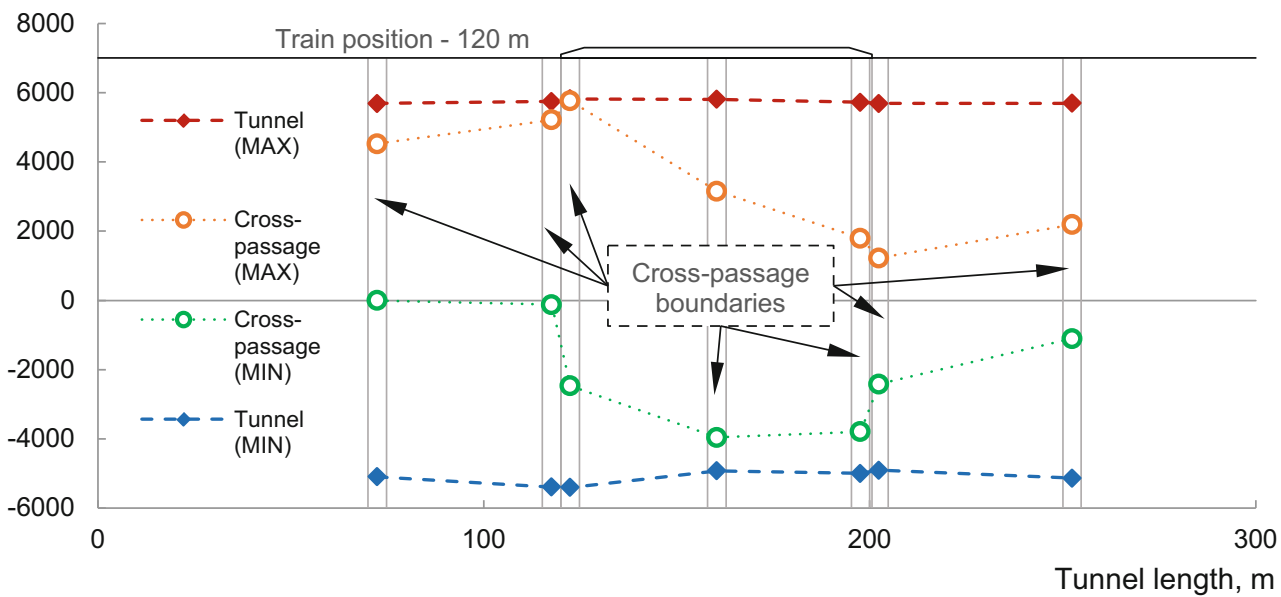

The cross-passage presence leads to side pressure oscillations near its correspondent boundaries (Fig. 4).

The volume pressure distribution inside the tunnel and cross-passage spans provides an additional description for the pressure pattern (Fig. 5). This approach shows the de- pendency between the train and cross-passage locations and emerging pressure loads.

Maximal and minimal pressure values for the tunnel model with each of the seven cross-passage locations were determined to provide knowledge on the limit levels that could be expected for the current model setup (Fig. 6). In- 
side the tunnel domain for all the considered cases, very similar pressure numbers are obtained as the biggest and smallest values arise at the train's nose and tail surfaces independently of the cross-passage position. However, the pressure inside the cross-passage domain is largely reliant on the cross-passage's and the train's mutual arrangement. The changes in maximal and minimal levels of pressure in the cross-passage area occur in accordance with the highand low-pressure zones around the train.

The cross-passage presence does not heavily affect the behaviour in mean pressure and mean velocity values while a significant mean velocity rise corresponds with a mean pressure drop due to the train's nose emerging, and the opposite effect is observed concerning the train's tail.

\subsection{Prediction of Aerodynamic Parameters for the Train-tunnel Model Considering the Surface Roughness}

The influence of the surface roughness on the aerodynamic characteristics is estimated for the train-tunnel model. A case with the biggest pressure numbers in the crosspassage area from the previous stage of this study is considered here-the cross-passage is located at a $120 \mathrm{~m}$ distance from the tunnel entrance.

For the simulation purposes, the following roughness values are adopted: for the concrete tunnel surfaces $-2 \mathrm{~mm}$; for the train body $-0.01 \mathrm{~mm}$ [18].

The surface roughness increases the resistance for the airflow inside the tunnel, which leads to a corresponding pressure loss change (Fig. 7). At the same time, no sufficient changes are observed in mean velocity, though the flow velocity in the vicinity of the tunnel and train surfaces
Fig. 7: The difference in mean pressure and mean velocity values caused by the surface roughness
Fig. 8: Pressure levels with averaged values for the tunnel and cross-passage spans

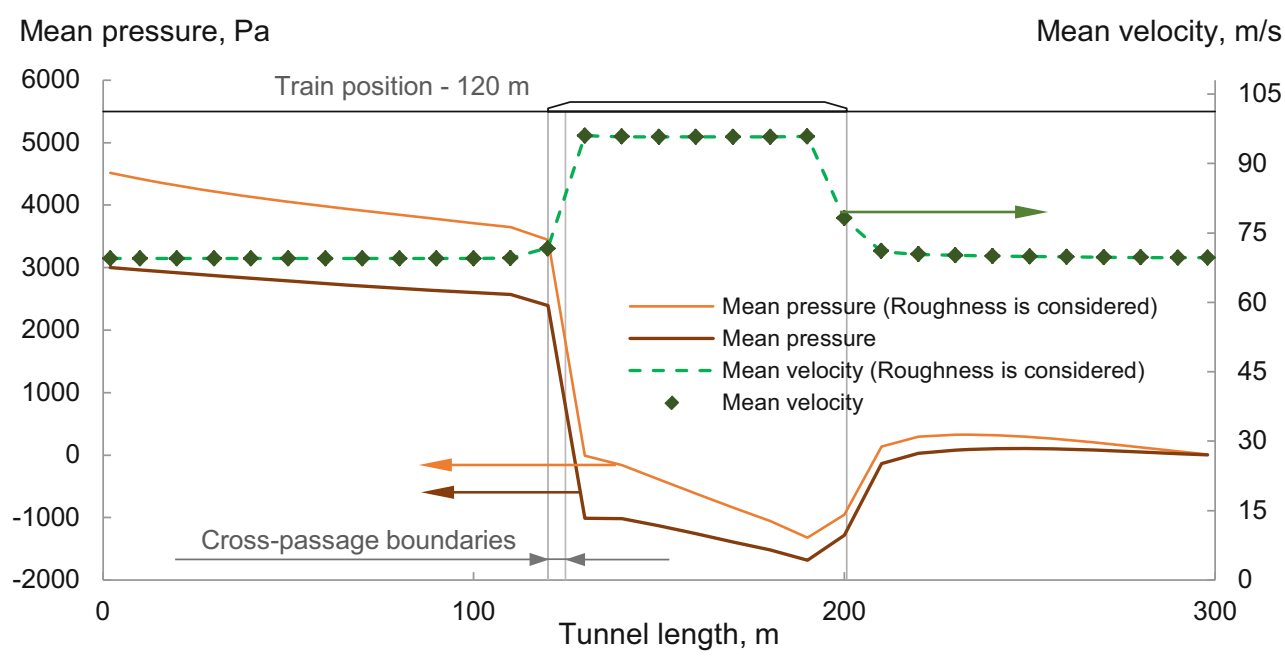

Pressure, $\mathrm{Pa}$

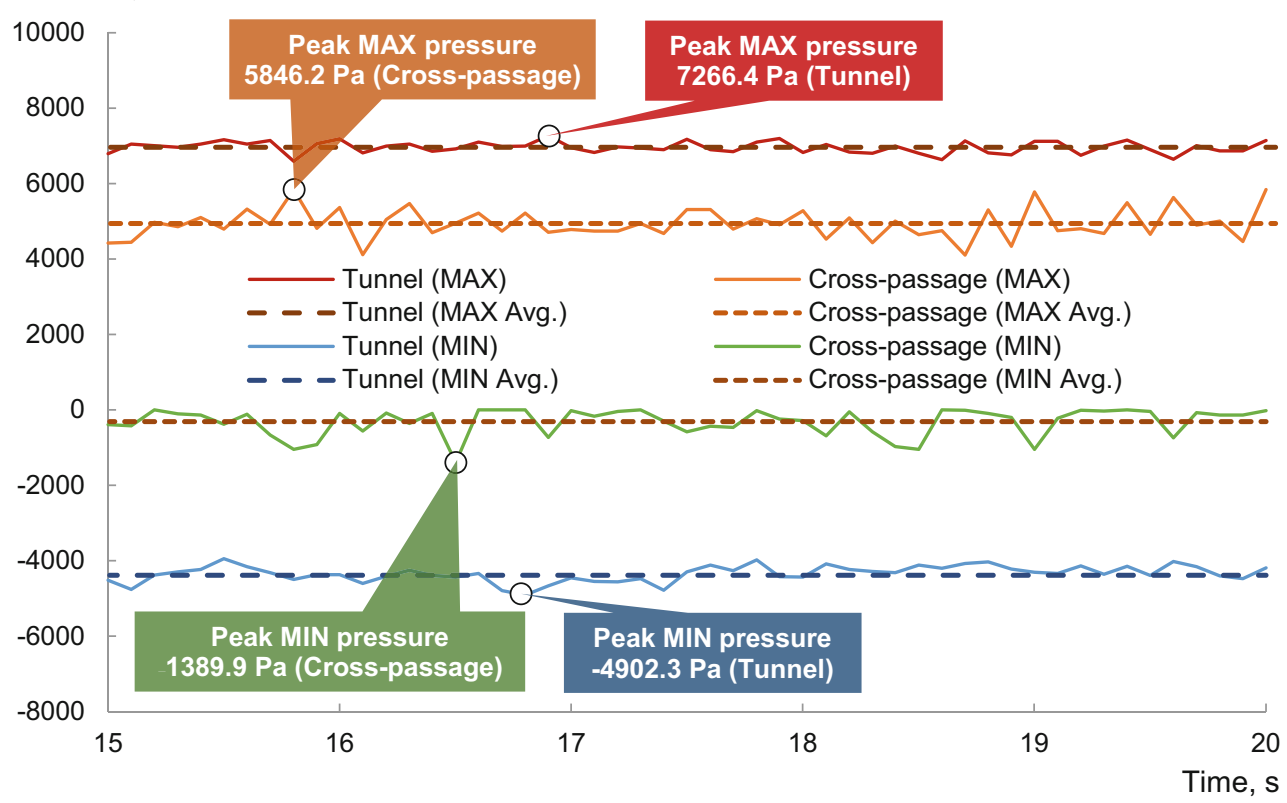



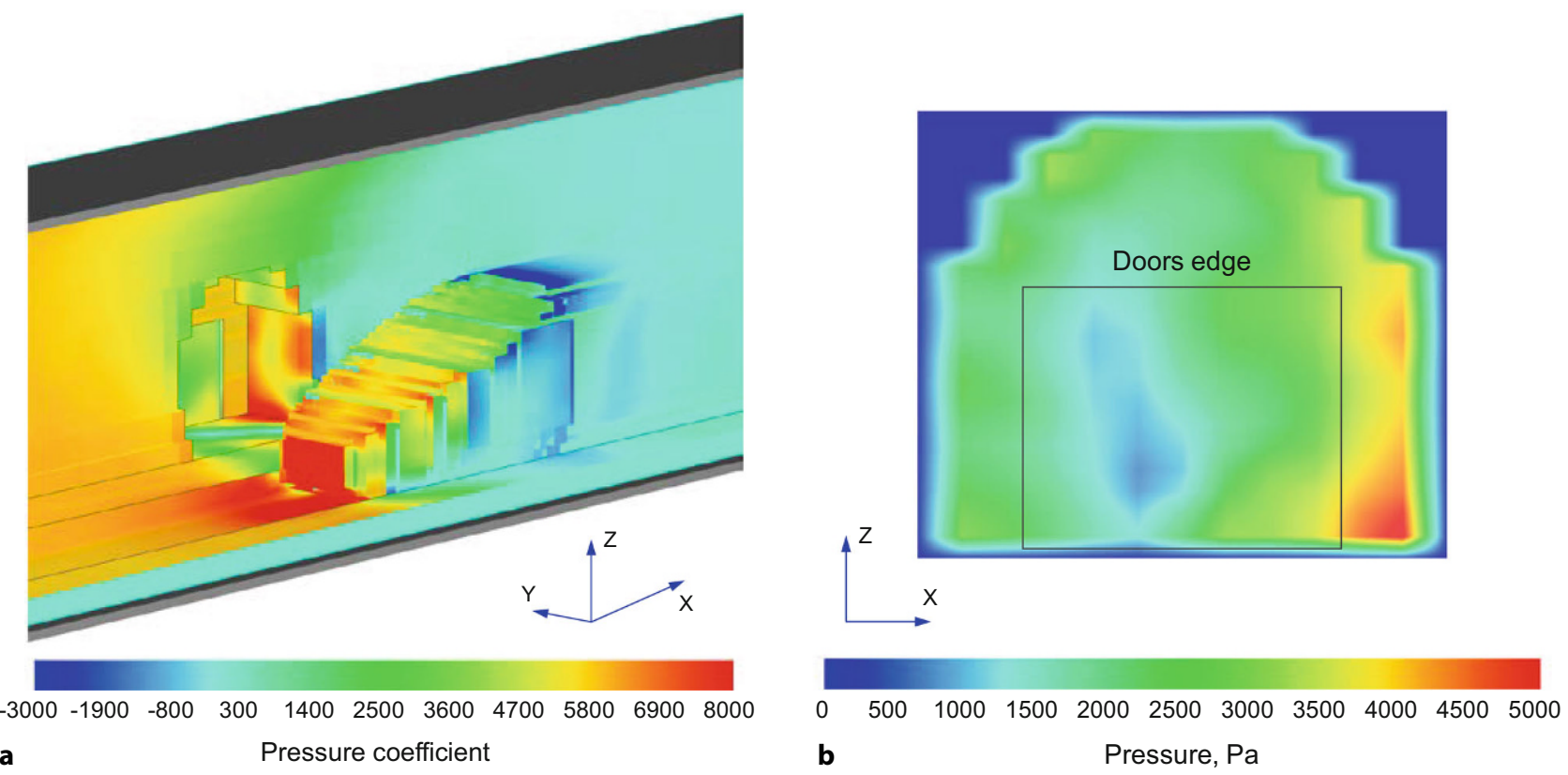

Fig. 9: Pressure distribution representation (at 18s of the simulation): a pressure coefficient; $\mathbf{b}$ planar slice of pressure values (the cross-passage wall with exit doors)

decreases compared to the case where roughness is not considered.

Through calculations, the maximal and minimal pressure levels for the tunnel and cross-passage spans were obtained (Fig. 8). Changes in the mentioned averaged parameters are given for the same period of a steady-state flow process-from 15 to $20 \mathrm{~s}$ of the simulation. Pressure peaks of maximal and minimal magnitude provide data for the pressure loading assessment.

Additionally, FDS features enable a 3D representation of the pressure distribution on the tunnel and train surfaces using the pressure coefficient (Fig. 9a). This visualization simplifies the detection of the most pressure loaded areas. It proves its worth in estimating the strength limits of the tunnel components and can be useful in predicting fatigue strength loading of the car body structure, for example.

The tunnel operating conditions set specific pressure patterns for the cross-passage area. The reliability of the fire-protection doors could be estimated due to the model calculations. Pressure distribution on a certain surface, e.g. the cross-passage wall with the escape doors (Fig. 9b), provides the necessary data to avoid undesirable issues including the occasional opening of the emergency exit doors by passing trains as early as the design stage.

\section{Conclusion and Outlook}

The FDS train-tunnel model development provides the basis for the aerodynamic load assessment within the scenario when a train passing at a high speed through a tunnel. The study shows how a cross-passage introduction to the tunnel and its location affects the pressure and velocity pattern.
The series of simulations show the possibility to obtain the data, which can be helpful during the design phases both for the train and the tunnel. For example, pressure coefficients on the train surface allow to evaluate the efficiency of the car body in terms of the induced air resistance, and the expected pressure levels on the fire-protection or escape tunnel doors can be used to examine their operational reliability. Yet, the FDS specific features such as its approach to creating obstructions should not be ignored and a model resolution should be carefully evaluated within the research purposes.

As of now, Fire Dynamic Simulator, whose main focus remains on smoke and heat transport, has difficulties in competing with other CFD analysis software in the fields relating to high-speed flows and the need to consider the interaction of moving objects. Nevertheless, there is a general expectation that the FDS involvement in these kinds of questions will drastically increase after the already announced plans to introduce unstructured discretization of governing equations for the built boundary conforming obstructions are implemented.

Funding. Open access funding provided by Montanuniversität Leoben

Open Access This article is licensed under a Creative Commons Attribution 4.0 International License, which permits use, sharing, adaptation, distribution and reproduction in any medium or format, as long as you give appropriate credit to the original author(s) and the source, provide a link to the Creative Commons licence, and indicate if changes were made. The images or other third party material in this article are included in the article's Creative Commons licence, unless indicated otherwise in a credit line to the material. If material is not included in the article's Creative Commons licence and your intended use is not permitted by statutory regulation or exceeds the permitted use, you will need to obtain permission directly from the copyright holder. To view a copy of this licence, visit http://creativecommons.org/licenses/by/4.0/. 


\section{References}

1. Baker, C. J.: A review of train aerodynamics Part 1-Fundamentals, The Aeronautical Journal, 118 (2014), no. 1201, pp 201-228, https:// doi.org/10.1017/S000192400000909X

2. Baker, C. J.: A review of train aerodynamics Part 2-Applications, The Aeronautical Journal, 118 (2014), no. 1202, pp 345-382, https:// doi.org/10.1017/S0001924000009179

3. ITA Committee on Operational Safety of Underground Facilities: Current practice on cross-passage design to support safety in rail and metro tunnels, ITA-COSUF Regulations, Guidelines and Best Practice, https://about.ita-aites.org/files/ITA-COSUF-REPORT_No3. pdf (27.09.2021)

4. Lierau, M.; Römer, M.: Tunnelfluchttüren - Erfahrungen und Erkenntnisse aus 20 Jahren Tunnelbau, GeoResources Zeitschrift, 3 (2016), S. 15-20

5. Zierl, D.; Liebwald, K.; Rossbacher, L.; Ebner, M.: Standardizing the Technical and Structural Specification of Doors in Tunnels, Tunnel Safety and Ventilation, 2014, https://lampx.tugraz.at/ tunnel2016/ history/Tunnel_2014_CD/Dateien/21_Liebwald.pdf (27.09.2021)

6. EN 14067-3:2003. Railway Applications-Aerodynamics-Part 3: Aerodynamics in Tunnels, Brussels: European Committee for Standardization (CEN), 2003

7. EN 14067-5:2006+A1:2010. Railway Applications-Aerodynamics-Par 5: Requirements and Test Procedures for Aero-dynamics in Tunnels, Brussels: European Committee for Standardization (CEN), 2010

8. Commission Regulation (EU) No 1302/2014 of 18 November 2014 concerning a technical specification for interoperability relating to the "rolling stock-locomotives and passenger rolling stock" subsystem of the rail system in the European Union, Official Journal of the European Union L, 356 (2014)

9. Ehrbar, H.; Gruber, L.; Sala, A. (eds.): Tunneling the Gotthard-The success story of the Gotthard Base Tunnel: STS Swiss Tunneling Society, 2016

10. Derkowski, P. et al.: High-Speed Rail Aerodynamic Assessment and Mitigation Report (2015): U.S. Department of Transportation, Federal Railroad Administration, https://railroads.dot.gov/sites/fra.dot.
gov/files/fra_net/15563/TR_High-Speed_Rail_Aero_Assessment final.pdf (27.09.2021)

11. Li, W.; Liu, T.; Chen, Z.; Guo, Z.; Huo, X.: Comparative study on the unsteady slipstream induced by a single train and two trains passing each other in a tunnel, Journal of Wind Engineering and Industrial Aerodynamics, 198 (2020), 104095, https://doi.org/10.1016/ j.jweia.2020.104095

12. Meng, S.; Li, X.; Chen, G.; Zhou, D.; Chen, Z.; Krajnovic, S.: Numerical simulation of slipstreams and wake flows of trains with different nose lengths passing through a tunnel, Tunnelling and Underground Space Technology, 108 (2021), 103701, https://doi.org/10. 1016/j.tust.2020.103701

13. Lu, Y.; Wang, T.; Yang, M.; Qian, B.: The influence of reduced crosssection on pressure transients from high-speed trains intersecting in a tunnel, Journal of Wind Engineering and Industrial Aerodynamics, 201 (2020), 104161, https://doi.org/10.1016/j.jweia.2020.104161

14. Miao, X.; He, K.; Minelli, G.; Zhang, J.; Gao, G.; Wei, H.; He, M.; Krajnovic, S.: Aerodynamic Performance of a High-Speed Train Passing through Three Standard Tunnel Junctions under Crosswinds, Applied Sciences, 10 (2020), no. 11, 3664, https://doi.org/10.3390/ app10113664

15. McGrattan, K. et al.: Fire Dynamics Simulator User's Guide, 6. ed., Gaithersburg, Maryland: National Institute of Standards and Technology, 2020, https://doi.org/10.6028/NIST.SP.1019

16. McGrattan, K. et al.: Fire Dynamics Simulator Verification Guide, vol. 2, 6. ed., Gaithersburg, Maryland: National Institute of Standards and Technology, 2020, https://doi.org/10.6028/NIST.SP.1018

17. Patsekha, A.; Galler, R.: Research@ZaB: Study of FDS Capabilities to Assess the High-Speed Train Impact on Pressure Pattern within a Railway Tunnel, BHM Berg- und Hüttenmännische Monatshefte, 166 (2021), no. 12, https://doi.org/10.1007/s00501-021-01170-7

18. Chanson, H.: Environmental Hydraulics of Open Channel Flows, Oxford: Elsevier Butterworth-Heinemann, 2004

Publisher's Note. Springer Nature remains neutral with regard to jurisdictional claims in published maps and institutional affiliations. 